\title{
New standards for neutral thermal environment of healthy very low birthweight infants in week one of life
}

\author{
P J J SAUER, H J DANE, AND H K A VISSER
}

Department of Paediatrics, Erasmus University and Academic Hospital Rotterdam, Sophia Children's Hospital, and Department of Applied Physics, Delft University of Technology, Delft, The Netherlands

SUMmARY It is generally accepted that low birthweight infants should be nursed at thermal neutral temperature - the environment in which oxygen consumption is at a minimum. Low birthweight infants do not, however, always show an increase in oxygen consumption at a temperature outside the neutral range, but react with a change in body temperature. We redefined therefore the neutral temperature for these infants as 'the ambient temperature at which the core temperature of the infant at rest is between 36.7 and $37.3^{\circ} \mathrm{C}$ and the core and mean skin temperatures are changing less than 0.2 and $0.3^{\circ} \mathrm{C} /$ hour respectively'. Using this definition, new guidelines of the neutral temperature have been made for healthy infants of 29-34 weeks' gestation. The neutral temperature during the first week of life is dependent on gestational age and postnatal age, whereas after the first week it depends on body weight and postnatal age. Using this definition and the guidelines, the appropriate environmental temperature for the individual patient can be chosen.

Since the studies done by Budin in $1900,{ }^{1}$ it is known that maintaining the body temperature and therefore controlling the environmental temperature is important for the survival of low birthweight infants. Glass et $a l^{2}$ showed that the environmental temperature also influences growth. Although short exposures to cold stress has a facilitative effect on thermogenesis in newborns, ${ }^{3}$ it is generally accepted that these infants should be nursed in an environment that keeps heat loss at a minimum. ${ }^{4}$ The optimal ambient temperature at which the infant should be nursed is called the thermal neutral temperature and is defined as 'the range of environmental temperature within which the metabolic rate is at a minimum and within which temperature regulation is achieved by non-evaporative physical processes alone'. 5

Several guidelines for the neutral temperature have been published. ${ }^{6-9}$ These guidelines cannot, however, be used alone for setting the incubator temperature, as the temperature of the walls of the incubator, ${ }^{10}$ humidity, ${ }^{11}{ }^{12}$ and air velocity ${ }^{13}$ are also important. Moreover, it is not known how the guidelines can be evaluated in individual patients, as it is impossible to measure metabolic rate continuously in each one. We defined the neutral temperature in a more practical way and have drawn up new guidelines using this definition.

\section{Methods}

Studies were done with a research incubator described previously ${ }^{14}$ in which it is possible to measure continuously oxygen consumption, carbon dioxide production, and heat loss through evaporation. The incubator is a closed system; oxygen consumption is measured with an accuracy of 0.2 $\mathrm{ml} / \mathrm{min}$ by measurement of the oxygen supply needed to maintain a constant concentration and carbon dioxide production is measured in a similar way. The incubator is double walled-water circulating between the two walls. The temperature of the walls can be regulated with an accuracy of $0 \cdot 1^{\circ} \mathrm{C}$ and changed by $0.4^{\circ} \mathrm{C} / \mathrm{min}$. The air entering the incubator is heated to the same temperature as the walls. The humidity of the air was set during the experiments at a dewpoint of $18 \cdot 0 \pm 0 \cdot 1^{\circ} \mathrm{C}$. The flow in the system is $10 \mathrm{l} / \mathrm{min}$.

During the study the following temperatures were recorded continuously using an Ellab universal digital thermometer DU-3 and thermocouples (Ellab, type AF6): mid-oesophagus, forehead, left 
hand, left upper arm, abdomen, left thigh, and left foot. The temperatures were measured with an absolute accuracy of $0 \cdot 1{ }^{\circ} \mathrm{C}$ and trends of $0 \cdot 1{ }^{\circ} \mathrm{C} /$ hour could be detected.

The infants were naked except for a very small plastic covered napkin to prevent evaporation from spilt urine and faeces. They were lying supine on a mattress made of netting with wide openings, so constructed that conductive heat loss was negligible. Only studies in which the infant was either sleeping or awake but quiet during the observation period were included for analysis. All infants were healthy at the time of the study.

Informed consent was obtained from all parents.

Definition of neutral temperature. The neutral temperature was defined as 'the ambient temperature at which the core temperature of the infant at rest is between 36.7 and $37.3^{\circ} \mathrm{C}$ and the core and mean skin temperatures are changing less than 0.2 and $0 \cdot 3^{\circ} \mathrm{C}$ /hour respectively' (see Discussion).

Patients. Twenty five studies were done during the first week of life in 14 infants of birthweight mean (SD), $1 \cdot 10(0 \cdot 41) \mathrm{kg}$ (range $0 \cdot 81-1.85 \mathrm{~kg}$ ) and gestational age 29-34 weeks. After the first week 78 measurements were done in 27 patients whose birthweights ranged from 0.81 to $1.85 \mathrm{~kg}$, and gestational ages from 29-35 weeks. Weight at study was mean (SD), $1.504(0.33) \mathrm{kg}$ (range 0.83-2.05 $\mathrm{kg}$ ); age 20 mean (SD), (8) days (range 7-35 days).

Statistical analysis. A multiple linear regression with backwards elimination was used to find the two most

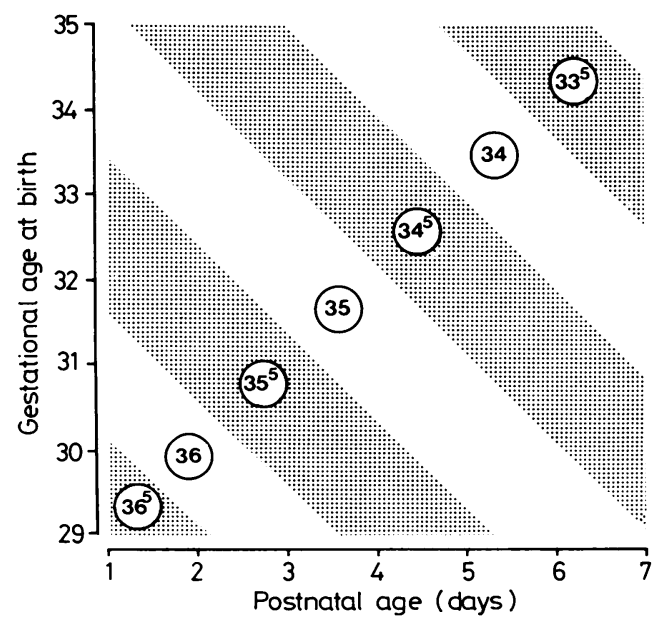

Fig. 1 Neutral thermal environment during the first week of life, calculated from the measurements.

Dewpoint of the air $18^{\circ} \mathrm{C}$, flow $10 \mathrm{Vmin}$.

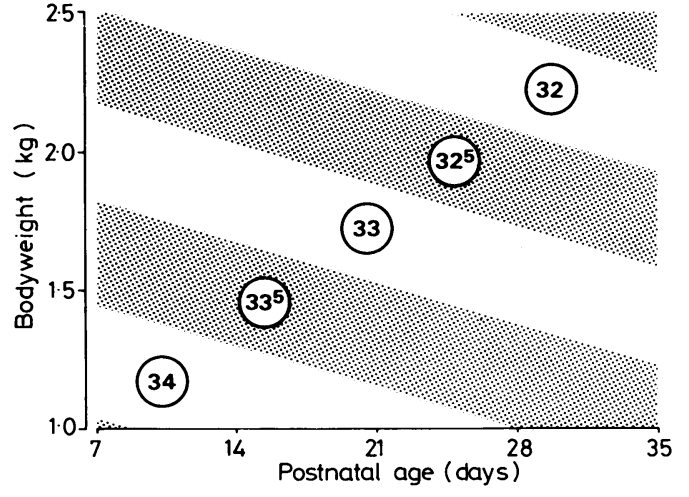

Fig. 2 Neutral thermal environment $\left({ }^{\circ} \mathrm{C}\right)$ from day 7-35.

Dewpoint of the air $18^{\circ} \mathrm{C}$, flow $10 \mathrm{Vmin}$. Body weight is current weight. Values for body weight $>2.0 \mathrm{~kg}$ are calculated by extrapolation.

significant parameters that influenced the neutral temperature. Four parameters were analysed: gestational age, birthweight, postnatal age, and actual weight.

\section{Results}

In each experiment the neutral temperature of the baby was obtained by changing the temperature of the incubator until the definition of the neutral temperature was met. The observation period after a change in environmental temperature was at least 45 minutes.

Neutral temperature during the first week of life showed a correlation with gestational and postnatal age $(r=0.82, P<0 \cdot 001)$ and can be expressed as follows: neutral temperature during the first week of life $=36.6-0.34 \times$ gestational age at birth $-0.28 \times$ postnatal age (equation 1) where temperature is expressed in ${ }^{\circ} \mathrm{C}$ and postnatal age in days. Gestational age is related to 30 weeks, for instance 28 weeks $=-2,32$ weeks $=+2$. The standard deviation of the temperature predicted with this formula is $0.7^{\circ} \mathrm{C}$.

The neutral temperature after the first week of life showed a correlation with postnatal age and body weight $(r=0.72, P<0.001)$ and may be written as: neutral temperature after the first week of life $=36-1.4 \times$ body weight $-0.03 \times$ postnatal age (equation 2) where neutral temperature is expressed in ${ }^{\circ} \mathrm{C}$, body weight in $\mathrm{kg}$ and postnatal age in days. The standard deviation of the temperature predicted with this formula is $0.65^{\circ} \mathrm{C}$.

All values apply to an environment with an equal air and wall temperature and a humidity of dewpoint of $18^{\circ} \mathrm{C}$. Neutral temperature charts made from equations 1 and 2 are shown in Figs. 1 and 2 . 


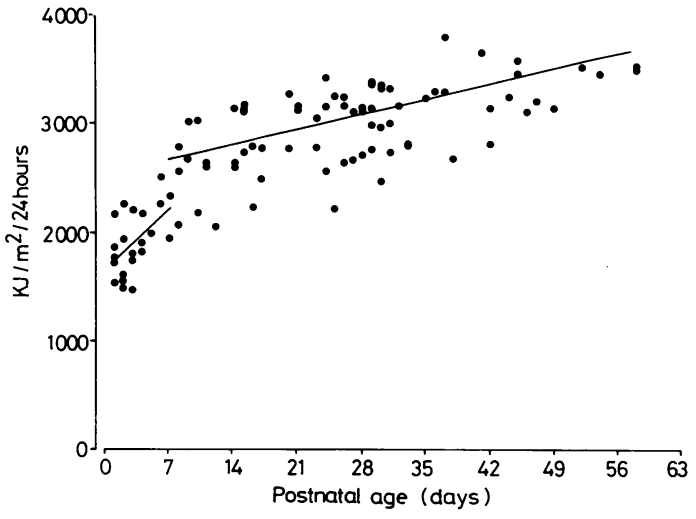

Fig. 3 Resting metabolic rate at the thermoneutral environment.

$$
\begin{array}{ll}
\multicolumn{2}{c}{Y=a \pm b x} \\
\text { Week 1 of life } & \text { After week 1 } \\
a=1642 \pm 86 & a=2507 \pm 35 \\
b=78 \pm 26 & b=17 \pm 3 \\
r=0.55 & r=0.87
\end{array}
$$

The resting metabolic rate, calculated from the oxygen consumption and the carbon dioxide production, was calculated at the neutral temperature for each infant. The results are shown in Fig. 3. The metabolic rate expressed per body surface area increased rapidly during the first week of life $(\mathrm{P}<0.01)$ and showed a gradual increase thereafter $(\mathrm{P}<0 \cdot 01)$.

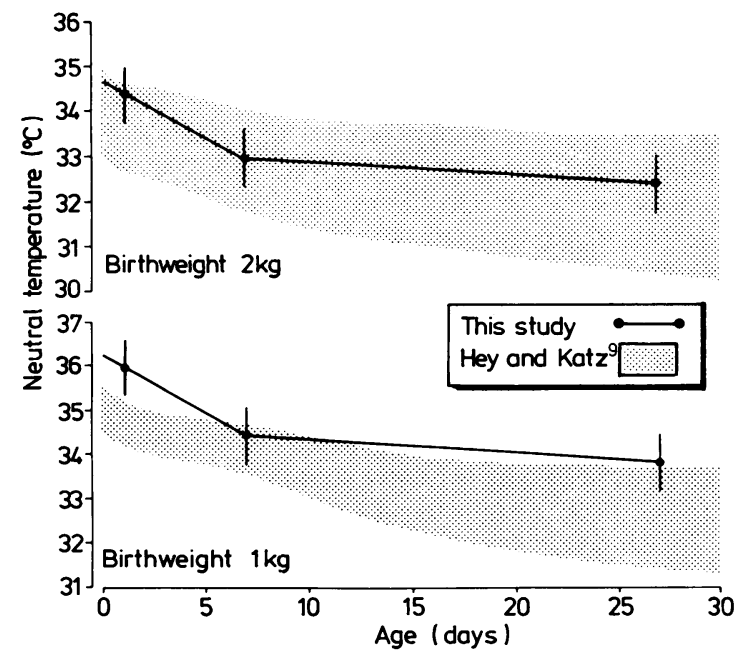

Fig. 4 Neutral temperature from this study, compared with the recommendations of Hey and Katz. ${ }^{9}$

\section{Discussion}

A baby produces heat continuously. All energy used for maintenance of the body, activity, and part of the energy for tissue synthesis, is given off as heat. ${ }^{14}$ A neonate will maintain his body temperature under optimal conditions without using extra energy especially for heat production. Total heat loss is dependent on both the heat production of the infant and the environmental conditions. Heat may be given off in an incubator via radiation, convection, and evaporation. ${ }^{15}$ The amount of heat given off in the different ways may vary, although total heat loss remains constant. ${ }^{16}$

As a reaction to a lower environmental temperature, the infant restricts skin perfusion which causes a drop in skin temperature. ${ }^{17}$ The core temperature will also change to obtain a new equilibrium with the environmental temperature. When the environmental temperature remains in the thermoneutral zone, the metabolic rate will not change and there will be a change only in the infant's temperature. When the environmental temperature drops below the thermoneutral zone, the metabolic rate will increase, accompanied by a drop in body temperature. 11 15 18-20

In our studies where we measured continuously core and skin temperature and metabolic rate, while changing the incubator temperature by $1^{\circ} \mathrm{C}$, we observed changes in the trend of core and skin temperature. We could not, however, distinguish changes in metabolic rate from spontaneous changes that occurred at a constant environmental temperature. Most studies have measured the increase in metabolic rate after a drop in environmental temperature of more than $1-2^{\circ} \mathrm{C} .^{11} 151819$ Bell et al $l^{20}$ found a $25-33 \%$ higher oxygen consumption at $1-2^{\circ} \mathrm{C}$ below the neutral zone compared with this zone. As the authors indicated, however, this increase might have been overestimated. Changes in body temperature were not recorded in this study, but the core temperatures were significantly lower at the lower temperature, nearly all being less than $36 \cdot 7^{\circ} \mathrm{C}$, which we considered as below the neutral zone.

We conclude from observations made during this study as well as those made by others ${ }^{16}$ that preterm infants often do not behave like mature homeotherm individuals. They react to a small change in environmental temperature with a change in body temperature rather than with a change in oxygen consumption. Under these circumstances, the physiologist's definition of the neutral temperature ${ }^{5}$ is difficult to apply. We therefore used the body temperature and changes thereof as an indicator of the neutral temperature in these infants. The age at 
which preterm infants really start to behave as fully competent homeotherm infants needs to be studied. The actual values used in our definition were chosen empirically.

Although published guidelines of the neutral temperatures $^{6-9}$ relate neutral temperature to body weight and postnatal age only, we found a correlation with gestational age rather than body weight during the first week. The high neutral temperature found at low gestational ages can be explained by the high evaporative heat loss found in very preterm infants. $^{21} 22$ As heat loss through evaporation may be equal to or even higher than total heat production, ${ }^{21}$ heat loss through radiation and convection must be minimal or even negative. The decrease in neutral temperature during the first week may be explained by a decrease in evaporative heat loss and an increase in metabolic rate and so in heat loss (Fig. 3). The decrease in neutral temperature after the first week is related to the increase in metabolic rate per body surface area (Fig. 3) and to the increase in body insulation due to the increase in subcutaneous fat. ${ }^{23}$

In Fig. 4 we compared our guidelines with the guidelines published by Hey and $\mathrm{Katz}^{9}$ for an infant of gestational age 33 weeks, and birthweight $2 \mathrm{~kg}$, and for an infant born after 29 weeks' gestation and of birthweight $1 \mathrm{~kg}$. It was assumed that both infants were growing $17 \mathrm{~g} / \mathrm{kg} /$ day after the first week of life. The values we found for the smaller infant are slightly higher, but for the infant of two $\mathrm{kg}$ there is complete agreement.

Our guidelines for the neutral temperature are only valid for an environment where wall and air temperatures are equal and the air has a dewpoint of $18^{\circ} \mathrm{C}$. When the wall temperature is lower than the air temperature, the air temperature must be raised according to the formula:

$\mathrm{T}_{\text {neutral }}=0.4 \mathrm{~T}_{\text {air }}+0.6 \mathrm{~T}_{\text {wall }} \cdot{ }^{9}$

The neutral temperature will be lower when the humidity of the air is higher than used in this study. In infants born after 29-34 weeks, the neutral temperature can be reduced by $0 \cdot 1^{\circ} \mathrm{C}$ for every increase in the dewpoint of the air of $1^{\circ} \mathrm{C} .{ }^{12}$ The exact influence of differences in humidity on the neutral temperature in very preterm infants needs to be studied. The air speed in the research incubator used is lower than the air speed in a conventional incubator. We estimated the air speed in our incubator to be $0.003 \mathrm{~m} / \mathrm{sec}$. The air speed in a conventional incubator is approximately $0.05-0.15$ $\mathrm{m} / \mathrm{sec}$. Stothers ${ }^{24}$ found that the total heat loss was equal at air speeds of 0.05 and $0.10 \mathrm{~m} / \mathrm{sec}$ in term infants. Increasing the air speed to $0.2 \mathrm{~m} / \mathrm{sec}$ caused an increase in total heat loss. The exact influence of air speed on the neutral temperature of preterm infants has still to be studied but the values of the neutral temperature, given in Figs. 1 and 2, should probably be increased slightly when an incubator with an air speed of more than $0 \cdot 1-0 \cdot 15 \mathrm{~m} / \mathrm{sec}$ is being used.

\section{References}

1 Budin P. 'Le nourisson', alimentation et hygiene des enfants debiles-enfants nés a tèrme. Paris: Octave Dion, 1900.

2 Glass L, Silverman WA, Sinclair JC. Effect of thermal environment on cold resistance and growth of small infants after the first week of life. Pediatrics 1968;41:1033-46.

${ }^{3}$ Perlstein PM, Mersh C, Glueck CJ, Sutherland JM. Adaptation to cold in the first three days of life. Pediatrics 1974;54:411-6.

${ }^{4}$ Hey EN. Thermal neutrality. Br Med Bull 1975;31:69-74.

${ }^{5}$ Bligh J, Johnson KG. Glossary of terms for thermal physiology. J Appl Physiol 1973;35:941-61.

${ }^{6}$ Brück K. Temperature regulation in the newborn infant. Biol Neonate 1961;3:65-119.

7 Oliver TK, Jr. Temperature regulation and heat production in the newborn. Pediatr Clin North Am 1965;12:765-79.

${ }^{8}$ Scopes JW, Ahmed J. Range of critical temperatures in sick and premature newborn infants. Arch Dis Child 1966;41:417-9.

9 Hey EN, Katz G. The optimum thermal environment for naked babies. Arch Dis Child 1970;45:328-34.

${ }^{10}$ Hey EN, Mount LE. Heat losses from babies in incubators. Arch Dis Child 1967;42:75-84.

${ }^{11}$ Hey EN, Maurice NP. Effect of humidity on production and loss of heat in the newborn baby. Arch Dis Child 1968;43:166-71.

12 Sauer PJJ, Dane HJ, Visser HKA. Influence of humidity on fluid loss and neutral temperature in low birthweight infants. Crit Care Med 1983;11:216.

13 Okken A, Bljham C. Influence of forced convection of heated air on insensible water loss in low birth weight infants. Pediatr Res 1981;15:674.

14 Sauer PJJ, Pearse RG, Dane HJ, Visser HKA. The energy cost of growth estimated from simultaneous direct and indirect calorimetry in infants of less than 2500 grams. In: Visser HKA, ed. Nutrition and metabolism of the fetus and infant. The Hague: Martinus Nijhoff, 1979:93-107.

15 Swyer PR. Heat loss after birth. In: Sinclair JC, ed. Temperature regulation and energy metabolism in the newborn. New York: Grune and Stratton, 1978:91-129.

16 Wheldon AE, Hull D. Incubation of very immature infants. Arch Dis Child 1983;58:504-8.

17 Brück K. Thermoregulation control mechanisms and neutral processses. In: Sinclair JC, ed. Temperature regulation and energy metabolism in the newborn. New York: Grune and Stratton, 1978:157-87.

${ }^{18}$ Heim T. Homeothermy and its metabolic cost. In: Davis JA, Dobbing J, eds. Scientific foundations of pediatrics. London: William Heinemann, 1981:91-128.

19 Scopes JW, Ahmed J. Minimal rates of oxygen consumption in sick and premature newborn infants. Arch Dis Child 1966;41:407-16.

20 Bell EF, Gray JC, Weinstein WR, Oh W. The effects of thermal environment on heat balance and insensible water loss in low-birth-weight infants. J Pediatr 1980;96:452-9.

21 Rutter N, Hull D. Water loss from the skin of term and preterm babies. Arch Dis Child 1979;58:858-68.

22 Hammarlund K, Nilsson GE, Oberg PA. Sedin G. Transepidermal water loss in newborn infants vs evaporation from the skin and heat exchange during the first hours of life. Acta Paediatr Scand 1980;69:385-92.

${ }^{23}$ Heimler R, Sumners JE, Grausz JP, Kiern CL, Glaspey JC. Thermal environment change in growing premature infants effect on general somatic growth and subcutaneous fat accumulation. Pediatrics 1981;68:82-6. 
${ }^{24}$ Stothers JK. The effect of forced convection on neonatal heat loss. J Physiol (Lon) 1980;305:77.

Correspondence to Dr P J J Sauer, Division of Neonatology, The
Hospital for Sick Children, 555 University Avenue, Toronto, Ontario, Canada M5G 1 X8.

Received 10 October 1983

\section{Editorial}

\section{Sunday after the war}

The Sunday after the war was for many children a time to look forward to when all the harrowing experiences would have passed, food would be in abundance, and families united. Delicacies such as oranges and bananas which were known only from their descriptions in books would be on the table for everyone to eat. Since we were going to win the war there would clearly be no shortages of anything afterwards. We spent hours planning what we would eat, what we would do, and whom we would see.

The great day came and went, and apart from a few fireworks and the different content of the 6 o'clock news it was difficult to see any difference between that Sunday and any other Sunday during the previous 6 years. How many times since then have we had the same sensation? The same sequence of events has occurred whenever attempts have been made to improve the child health services in this country. Pressure, both professional and public, has resulted in the setting up of a royal commission and while this has been taking evidence complete lack of progress has been assured. After several years' work the report is published and often is not even discussed by those who commissioned it. Those who look forward to essential changes soon realise that 'Sunday after the war' is a device to keep them quiet for a few years.

These remarks apply to many reports and especially the Platt, Court, and Short reports. The reports on the training of senior and clinical medical officers are developing ominous signs of the same destiny. Our columns have recently shown evidence that unless there is an increase in consultant paediatrician posts many well trained junior staff have no prospects of attaining definitive posts. Less than a year ago we were reassured that the number of consultant posts would be increased by a substantial proportion before the end of this century. The latest cuts in staffing within the National Health Service show that this will not be attained. Why do we still cling to the illusion that there is a 'Sunday after the war'? 